\title{
Waste Minimisation in Office Refurbishment Projects: An Australian Perspective
}

\author{
Mary Hardie ${ }^{*}, 1$, Graham Miller ${ }^{2}$ and Shahed Khan ${ }^{3}$ \\ ${ }^{I}$ School of Engineering, University of Western Sydney, Locked Bag 1797, South Penrith Distribution Centre, NSW, \\ 1797, Australia \\ ${ }^{2}$ 4/16 Filburn Street, Scarborough, WA 6019, Australia \\ ${ }^{3}$ Department of Urban and Regional Planning, Curtin University of Technology, GPO Box U1987 Perth, WA 6845, \\ Australia
}

\begin{abstract}
The refurbishment of commercial buildings is growing as a percentage of overall construction activity in Australia and this trend is likely to continue. Refurbishment generates a significant waste stream much of which is potentially reusable or recyclable. Despite this potential, several factors are known to inhibit the amount of recycling that actually occurs on renovation projects. In order to identify the reasons causing this reluctance, a process of monitoring a project and consultation with experts in the area was carried out. Twenty three experts experienced in commercial refurbishment projects and three waste contractors with specific knowledge of construction waste were interviewed. Waste receipts for an ongoing case study project were monitored. Three major factors were found to inhibit recycling rates: the presence of any form of asbestos in the building; the continued occupation of the building during construction; and the breaking up of a large project into small separate contracts for different stages of the refurbishment so that there were no economies of scale for the contractor who wanted to recycle. Current rates for reuse and recycling of materials were collected from the experts. The results revealed a considerable variation in practice between companies and indicated areas which should be targeted to improve performance.
\end{abstract}

Keywords: Waste minimisation, recycling, reuse, refurbishment projects, asbestos, Australia.

\section{INTRODUCTION}

Studies in the UK have demonstrated the sustainability benefits of office refurbishment when compared to demolition and rebuilding [1]. The desire for more sustainable building practice is one of the factors driving the trend towards renovation and refitting of existing building premises rather than new construction in many parts of the world [2]. In addition to the environmental imperative, property values and planning restrictions are combining to make renovation an economically attractive alternative to demolition and rebuild, especially on CBD (Central Business District) sites. All refurbishment, however, generates some amount of solid waste and generally this is at a higher rate than new construction for a given floor area. According to a major commercial property analysis group's newsletter, the office building stock in the major Australian cities can be described as 'mature', that is, either refurbished some time ago or reaching a stage where major refurbishment is necessary. More precisely in Sydney the average age of office buildings is 28 years and the average time since initial construction or the most recent refurbishment is 19 years [3]. On the assumption that office buildings usually require a major refurbishment every 20 to 25 years, it can be expected that commercial refurbishment activity is likely to be a

*Address correspondence to this author at the School of Engineering, University of Western Sydney, Locked Bag 1797, South Penrith Distribution Centre, NSW, 1797, Australia; Tel: +61 024736 0921; Fax: +61 024736 8333; E-mail: m.hardie@uws.edu.au significant and increasing portion of overall construction activity for the foreseeable future. Consequently if the refurbishment sector is to be environmentally responsible there is a need to find suitable recycling and waste management techniques in order to avoid overburdening the already heavily utilised landfill system. The objective of this research is to monitor a sample of current recycling and reuse rates as reported by experts involved with commercial refurbishment projects in three Australian cities, namely Sydney, Brisbane and Melbourne.

\section{Impediments to Reuse and Recycling}

There are several commonly cited impediments to waste minimisation in general construction projects and several authors have looked at the process. Factors identified include: available space and time restrictions that have been shown to limit on site sorting of the waste stream [4-9]; work practices and attitudes that may militate against reuse and recycling [10]; small quantities of a recyclable material that may be uneconomic to sort and transport to a recycling facility [11]. It is likely that several of these problems may be heightened in the more restricted area of refurbishment projects where specific management skills are needed [12].

Raising the level of reuse and recycling on construction projects has been a stated aim of Australian regulatory authorities for some time. The construction of facilities for the Olympic Games in Sydney in 2000 gave impetus to this policy and several initiatives were set in place to ensure the environmental impact of the Olympic venues was 
minimised. Among these initiatives was the WasteWise Construction program which was established in 1995 as a partnership between the Australian government, major construction companies and industry organisations [13]. The program represented a major step forward in on site sorting and separation of construction waste. Targets were set and achieved for up to $50 \%$ diversion of material from landfill by 2000. Unfortunately, when the program finished in 2001 considerable impetus was lost and there is evidence of some return to former wasteful practices.

\section{Incentives for Waste Minimisation}

The principal incentive for waste minimisation on construction sites remains an economic one. There are, however, other drivers of waste minimisation initiatives. One of these is site safety. A well organised, controlled and monitored construction site where materials inflows and outflows are carefully tracked is likely to have fewer problems with accident and injury due to trips and falls. A frugal attitude towards materials can encourage the whole workforce on site to look for efficiencies and savings and to consequently avoid waste. Studies have shown that the workforce can take ownership of these issues and actively participate in waste management $[14,15]$. The desire to minimise the environmental damage done by construction waste has led to the development of systems for assessing, tracking and managing such waste [16]. This trend has been observed in several countries and is likely to continue [17].

\section{Effect of 'Green Ratings'}

Increasingly the commercial office building market in Australia is being influenced by a customer desire to score well on the various forms of green rating schemes which are now available. There are several schemes for environmental rating of buildings currently in use.

NABERS (National Australian Built Environment Rating System) is a voluntary performance based rating system that can be used for the existing building stock. NABERS rates a building on the basis of its measured operational impacts which include energy, refrigerants (greenhouse and ozone depletion potential), water, stormwater runoff and pollution, sewage, landscape diversity, transport, indoor air quality, occupant satisfaction, waste and toxic materials. As it does not look at the building or renovation process, it does not specifically assess recycled content or construction waste minimisation.

The Australian Building Greenhouse Rating Scheme (ABGR) provides market recognition and a competitive advantage for low greenhouse emitting and energy efficient buildings. The scheme encourages best practice in the design, operation and maintenance of commercial buildings to minimise greenhouse emissions. Administered nationally by the NSW Department of Energy, Utilities and Sustainability (DEUS) and locally by leading state greenhouse agencies, the ABGR scheme rates buildings from one to five stars with five stars representing exceptional greenhouse performance. Current market best practice in Australia is three stars. As ABGR applies to both existing and new buildings it is particularly useful for modelling the effect of a refurbishment project. The use of recycled materials and waste minimisation practices are not, however, specifically addressed.

The Green Building Council of Australia's 'Green Star' rating has eight environmental impact categories: management; indoor environment quality; energy; water; materials; land use and ecology; transport; and emissions. There is some allowance for the inclusion of recycled and recyclable materials.

The LCADesign (Life Cycle Assessment) tool is currently being upgraded by researchers at the Australian Cooperative Research Centre for Construction Innovation to include recycled content as a component layer in its decision making tool for designers. It is likely that this element of recycled and recyclable content in buildings will increasingly be included in green rating tools as more data becomes available about the potential energy and emission savings for building material recycling.

For the moment, however, such ratings are unlikely to have a significant effect in lifting recycling performance in office building refurbishments.

\section{MATERIALS AND METHODS}

In order to determine the current state of reuse and recycling practice in Australian commercial refurbishment projects a structured interview process with industry practitioners and consultants was undertaken to give a snapshot of current practice. As data on reuse and recycling rates in commercial refurbishment projects is likely to be held in different formats by different project participants, there is a comparability problem when collecting data across projects and companies [18]. As a result it was decided to seek expert opinion from individuals involved at varying stages and in varying capacities in refurbishment projects and to ask for the reuse and recycling rates that were currently being achieved in such projects. The experts were identified through recommendations by members of the Australian Cooperative Research Centre for Construction Innovation. The experts approached included environmental consultants specialising in waste management as well as other consultants such as architects and quantity surveyors who were known to have been involved in successful and award-winning office refurbishment projects. In the case of contractors involved in refurbishment work, the person responsible for waste management within the organisation was identified. These ranged from construction managers to engineers, OH\&S/environment managers or demolition/ strip-out specialists. Contractors specialising in handling and removing waste were also consulted and in each case the person responsible for construction and demolition waste was interviewed/surveyed. The majority of the respondents are from companies specialising in general commercial construction.

Respondents ranged from some of Australia's largest construction companies to small specialist contractors in commercial strip-outs. A total of twenty six experts were interviewed or surveyed. Some were only able to provide a limited response. For example contractors specialising in waste could tell us little about Waste Management Plans which occur at the approval stage of a project, but they were able to provide specific information about quantities and recycling potential of different materials. 
Of the twenty six experts interviewed/surveyed, ten involved face-to-face meetings, twelve were conducted by telephone and four were conducted through email. Face-toface interviews/surveys were recorded and transcripts prepared as well as notes taken by the interviewer. Data was collected from respondents in New South Wales, Victoria, Queensland and the Australian Capital Territory. Most respondents had interstate experience and one had national responsibility for waste management issues in a large construction/property corporation. Most of the experts had more than ten years experience in the construction industry with fifty percent having more than twenty years experience. Those with fewer than ten years experience were generally site managers who had day to day contact with waste minimisation issues.

The experts were asked 25 questions on waste minimisation practices, attitudes, drivers and inhibitors. Then in order to overcome an initial reluctance by many of the experts to provide data which they considered 'commercially in confidence', rates of recycling of building materials were collected in two ways. Initially an estimate of the percentage of recycling for five common building materials was asked for. Later a more complex break down of building elements was requested. The information received from the experts in the initial interviews was used to inform the format of a spreadsheet of building components classified into more detailed categories for the second round of data collection. Confidentiality of the information provided by those interviewed/surveyed was requested and assured. The researchers retain the names and positions of the individual respondents as well as the companies they are associated with for verification purposes but this information will not be linked to any of the published data.

\section{RESULTS AND DISCUSSION}

\section{Concrete, Timber, Steel, Plasterboard, Glass}

In the initial survey the experts were asked to provide information on current typical total percentage of reuse and recycling that are achieved in refurbishment project for concrete, timber, steel, plasterboard and glass. There was considerable agreement among the expert respondents on this matter with consistently high average rates specified for concrete and steel, mid level rates for timber and glass and low rates for plasterboard. Back up surveys and interviews confirmed the results. There were, however, some outlying rates given, particularly by high volume recyclers. These outlying scores were not confined to any individual so it was decided to create a weighted average by discarding the highest and lowest score in each range to achieve a rate that more accurately represents typical current practice. The average and the weighted average rates are shown in Fig. (1) below.

The intrinsic value of steel scrap has meant that it is now standard practice to separate ferrous metal from construction waste and only residual amounts in unseparated components end up in landfill (see Fig. 2 below). The recycling of concrete has been greatly encouraged by the cost of sending bulk waste to landfill and consequently systems are now in place to crush and recycle concrete waste whenever it is

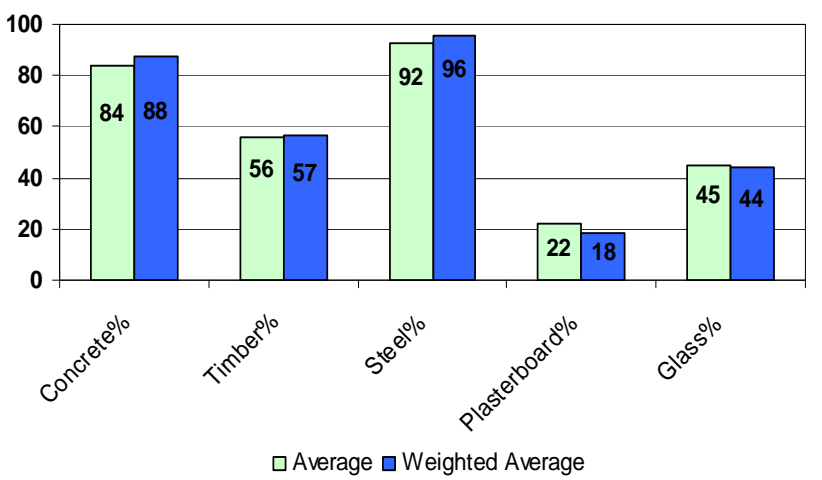

Fig. (1). Reuse/Recycling Rates for common building materials in commercial refurbishment projects.

generated in sufficient quantities in refurbishment projects. Timber is both reused and recycled but this is very dependent on section sizes and the quality of the secondhand material as illustrated in Fig. (3) below. The situation with glass is complex. Window or architectural glass cannot be recycled along with container glass because of different melting points due to additives and coatings. Recycling plants have to be set up specifically to cater for window glass and while some of these exist, the option is not commonly available throughout Australia. Plasterboard from refurbishment projects represents a significant problem and much of it is currently destined for landfill. It is possible to use off-cuts from new plasterboard as feedstock in the plasterboard manufacturing process and there are industrial uses for gypsum recycled from old plasterboard but it appears not much of this is occurring in Australia outside Victoria at the moment. The information collected from the experts in the initial interviews was used to inform the format of a spreadsheet of building components classified into more detailed categories. The information collected is described in the next section.

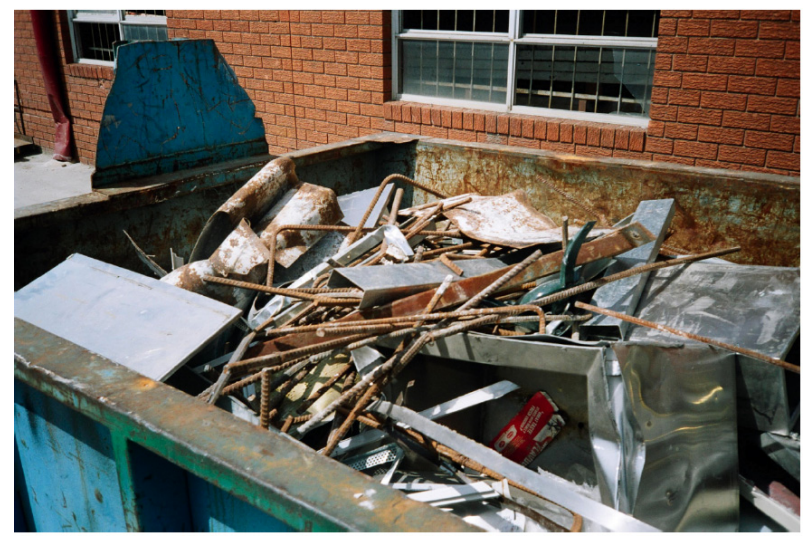

Fig. (2). Metals bin at Sydney demolition yard. Photo A. O'Donnell.

\section{Findings on Current Rates}

Fifteen of the twenty six participants in the expert consultation process provided their best estimates of reuse and recycling rates that are currently being achieved in office refurbishment projects. The breakdown of the respondents providing rates was 9 practitioners, 5 consultants and 1 waste contractor. For the purposes of this study 'Reuse' refers to a 


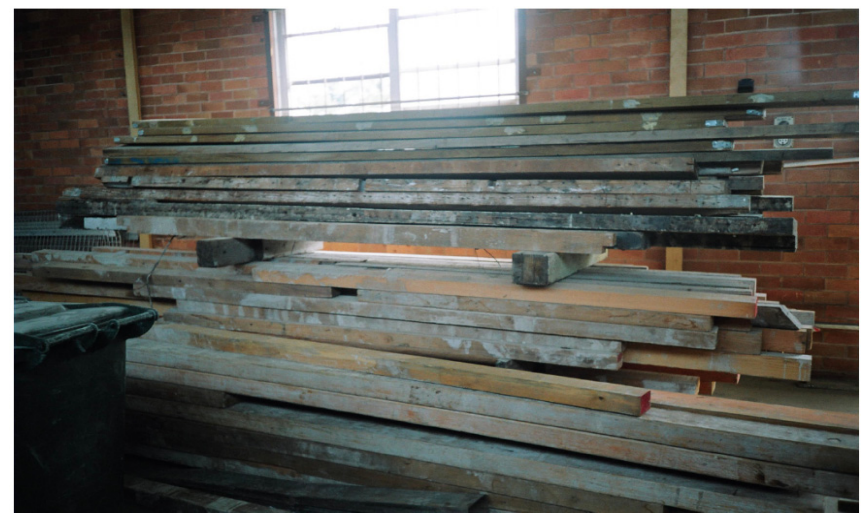

Fig. (3). Timber recovered for reuse. Photo A. O'Donnell.

second life for a building material or component without significant alteration or transformation. 'Recycling' refers to the use of salvaged material as feedstock for new material. Significant transformation and reprocessing is involved in the case of recycling. In addition, the expert respondents were asked to distinguish between reuse on site, reuse off site, recycling on site and recycling off site. The amount of data collected was significant and the correlations between sections and respondents are complex. The average of the responses for components in the four categories of building fabric, fittings, finishes and service components is presented in Figs. (4-7) below. Some general results can be gleaned from the figures for the four component categories and some trends are emerging.

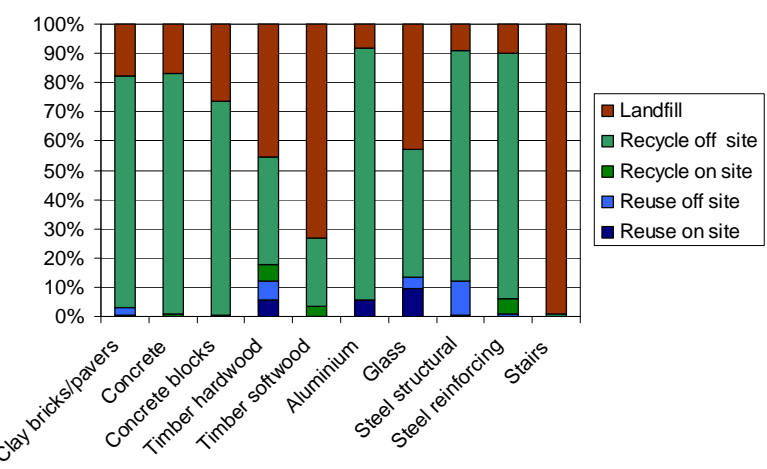

Fig. (4). Destination of Building Fabric Components in commercial refurbishment projects.

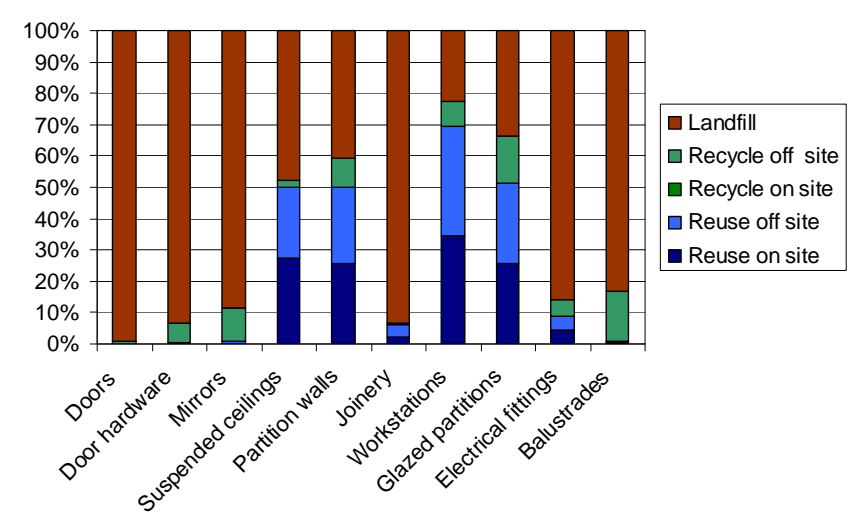

Fig. (5). Destination of Fittings Components in commercial refurbishment projects.
The building fabric removed in a commercial refurbishment project is likely to receive a significant level of recycling at present. Almost all of this recycling happens off site. Aluminium, structural steel and steel reinforcing are reportedly recycled at the rate of $86 \%, 79 \%$ and $84 \%$ respectively. Heavy masonry materials like bricks, blocks and concrete are also commonly recycled (rates of over $70 \%$ for each element). Stairs were the only element whose prime destination was landfill and this is probably due to their highly customised nature. Landfill was the principle destination reported for most fittings removed from refurbishments except for suspended ceilings, partition walls, workstations and glazed partitions. Workstations were commonly reused both on and off site (35\% each category). Very little recycling was reported for fittings. The majority of all finishes removed during refurbishments end up in landfill and no recycling on site was reported. Reuse for carpet is reportedly a growing area. Plasterboard recycling was an area of considerable disagreement among the experts. While several reported that no recycling occurred, a few were able to report high levels of recycling. The differences appear to be location based with Victorian recycling facilities being widely available while very little plasterboard recycling occurred in other states. Finally, high levels of recycling off site occur with most services components but there was very little reuse reported. Refrigeration components appear to lag other services components in having recycling facilities available.

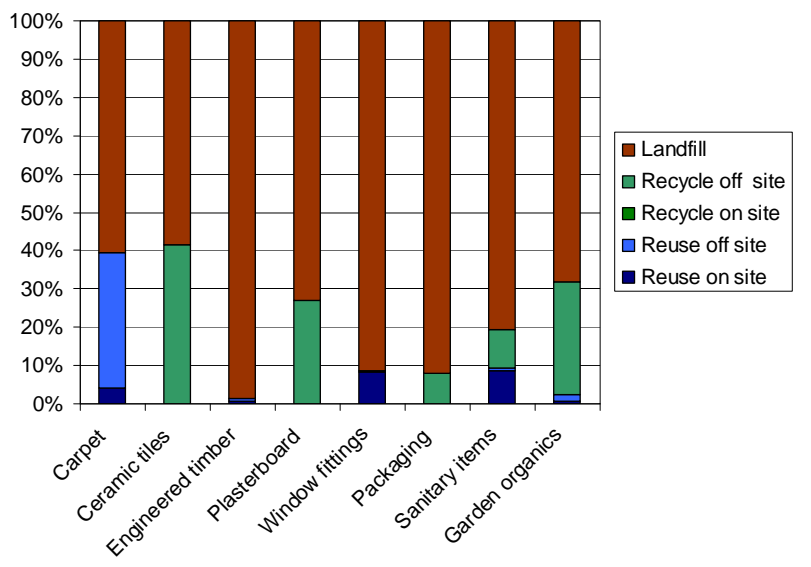

Fig. (6). Destination of Finish Components in commercial refurbishment projects.

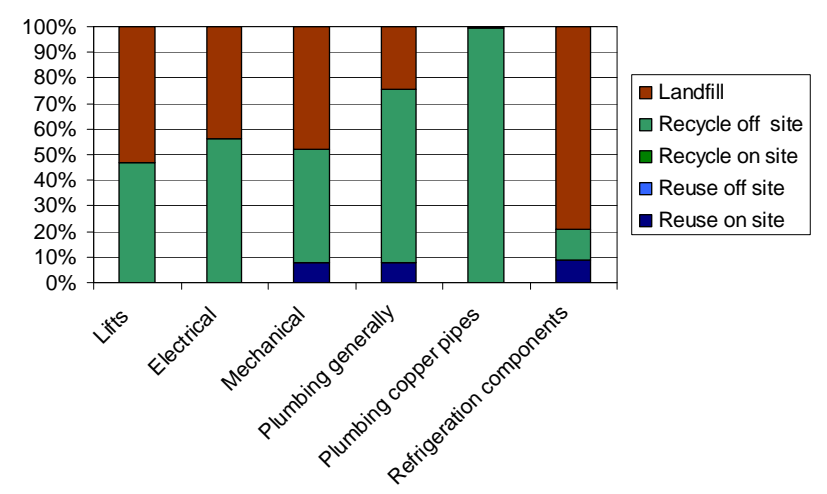

Fig. (7). Destination of Services Components in commercial refurbishment projects. 


\section{Qualitative Survey Responses}

The twenty six experts consulted gave commentary on the larger issue of construction waste management. They were asked about their attitudes to the current system of waste management in commercial refurbishments and the areas where they saw potential for improved performance. Some general themes can be drawn from their commentaries.

The use of Waste Management Plans varied widely among the interviewees. Experts were asked how often Waste Management Plans were required as well as how often they were monitored. Most of those who indicated that a high level of monitoring occurred on their projects also indicated that the monitoring was essentially an in-house reporting requirement. There does not appear to be any significant regulatory monitoring of waste arising from refurbishment projects. The utility of Waste Management Plans was questioned by a number of the respondents, as indicated by the following comment from one of the interviewees:

\section{"Most references to environmental manage- ment are cosmetic, the paperwork just has to be done".}

A more effective means of planning for waste minimisation is likely to be needed if rates of reuse and recycling are to be significantly lifted.

Responses to the questions relating to references to waste minimisation in various contractual forms were similar to that of Waste Management Plans. Generally a broad statement relating to waste minimisation would often be included in both Head Contracts and Subcontracts. However, it seems from this survey response that rarely is waste minimisation addressed at the level of a Bill of Quantities in Australia.

There have also been indications from some of the larger commercial operators interviewed that there is a trend towards engaging one waste contractor across all company sites for up to three years. This is similar to many domestic waste collection operations for local Councils. It has been suggested that this trend has implications for the level of onsite sorting that is likely to occur in future projects. The question of whether on site sorting or waste contractor sorting produces better outcomes is yet to be thoroughly studied. Some expert interviewees favoured the latter approach:

\section{"We have a good arrangement with our waste contractor where offsite sorting is subject to periodical audits".}

Determining the point in the refurbishment process at which waste sorting most usefully occurs is a suitable topic for future research.

One of the principal difficulties encountered in studying the area of waste management in construction is that there appears to be no standard method of actually measuring waste on a commercial refurbishment project, and consequently, the various stakeholders choose to measure waste differently. Most waste management plans require cubic metres or tonnage of various materials to be listed. Volume is of primary concern to some stakeholders whereas weight is more important to others as weight is linked to tipping fees and the various waste levies applied throughout the states. Other forms of measurement include number and size of bin movements, cost per square metre of the refurbishment and estimates from site drawings. Some expert respondents simply stated that waste is not generally measured on commercial refurbishments at all and destinations are not recorded. One interviewee explained this by saying:

\section{"Demolition is usually part of the Prelimin-} aries, which are considered an overhead".

Generally most respondents reported considerable positive change in waste management procedures in the time since they commenced working in the industry. While most regarded cost as the most significant factor in decision making about waste outcomes, they were also willing to consider environmental issues as part of the equation for determining waste management regimes. One stated that:

$$
\begin{aligned}
& \text { "We will pay a little more to do the right } \\
& \text { thing". }
\end{aligned}
$$

Despite the differences of opinion with regard to measurement, monitoring and responsibility for waste minimisation, there were some areas which were signalled out as having potential for significant improvement. These are discussed below.

\section{Some Suggested Target Areas}

Plasterboard has been identified as a material that receives different treatment in different regional areas. It is often recycled in Victoria and to a lesser extent in New South Wales but rarely in Queensland. Making best practice in this area standard practice throughout Australia is a matter of spreading both information and recycling facilities. Reinforcing steel is still not recycled as a general rule although the more committed recyclers manage to achieve $100 \%$ rates. This is an area where performance can reasonably be lifted.

The reuse of components such as sinks, basins, cupboards, benches and other fittings from commercial refurbishments still seems to be occurring at fairly low levels. Perhaps an internet based system which advertises these items for sale or removal at the strip-out stage of projects might be worth consideration on a city or state-wide basis. They may also be donated to community or charitable groups. A more systematic monitoring of outcomes from commercial construction refurbishments is likely to lift awareness of the issues and potential as well as aiding in the identification of areas of underperformance in current projects and the setting of targets for future projects.

\section{Case Study Project - Preliminary Findings}

While the expert consultation process was taking place it was decided to seek some measurable verification of the data being gathered through means of a case study project. This proved to be problematic as those responsible for large office buildings undergoing major refurbishments tend to want to keep their records private so that confidential commercial information relating to construction contracts is not revealed to competitors. The researchers did manage to get permission to track the waste outcomes from the 
refurbishment of a 22 storey government office building in Sydney. The building was constructed in 1979 and had had no major refurbishment since that time. The building was to remain continually occupied during the refurbishment and consequently the project was staged over a five year period. It is expected to be completed by the end of 2010 .

The study is ongoing but there are some preliminary findings which have correlated with the comments made by several of the experts in the consultation process. Firstly, the presence of asbestos insulation in the inter-floor and duct spaces in the building severely constrained the scheduling of the refurbishment and limited the amount of material recycling that ended up being done. Secondly, the continued occupation of the building during refurbishment had the result of stretching the project progress over a long period of time. Major work had to done in short bursts over the holiday periods and there was very little opportunity for on site sorting or for storage of items for later reuse elsewhere in the building. Thirdly, due to scheduling difficulties because of the need to accommodate continued operation of the building and continued public access the decision was taken to break a very large project into discrete small contracts for the various stages of the work. This has meant that there is little incentive for individual contractors to sort, store and salvage material in small quantities. Each of these issues will be discussed in greater detail.

\section{Presence of Asbestos}

Office buildings constructed in the fifties, sixties and seventies commonly have some asbestos based products which were formerly used for insulation and fire protection purposes. If left undisturbed this material is unlikely to be a hazard but when airborne fibres are released by renovation work they represent a significant risk to human health. As a result asbestos removal is covered by strict regulation and remediation protocols (National Occupational Health and Safety Commission 1988). The presence of asbestos in a renovation was nominated as a factor which affects the feasibility and cost by eleven out of twenty four members of the expert consultation group in response to an open ended and unprompted question. Some experts reported that mere proximity to small quantities of hazardous materials such as asbestos can render otherwise recyclable materials as contaminated. One waste contractor reported that the suspicion of asbestos being present in the source material could rule out the crushing of concrete for road base. This was confirmed by the case study project where, in the initial refurbishment stage, all the waste was classified as containing asbestos. This included timber, floor coverings, sanitary fittings and built in furniture which were highly unlikely to have contained any asbestos fibres.

\section{Continued Occupation}

The disruptive effects of continued occupation during a refurbishment project have been closely studied from a valuation perspective [19]. There are also significant effects on construction scheduling and safety issues. More frequent and costly late design iterations are likely to occur as occupants watch the progress of the renovation work in other parts of the building [20,21]. The expert group consulted for this research had mixed views on the continued occupation of a building during refurbishment. Thirteen experts considered it a significant issue. They stated that it would add time to the project and would restrict space for stockpiling of sorted waste. The renovation works might also affect the indoor environment quality for the occupants and result in complaints to the contractor. On the other hand five experts felt that continued occupation of the building did not affect the viability of a project. They were aware of the issues raised by other experts but felt that any such problems could be handled with good management processes.

\section{Separating a Large Project into Small Parcels}

The case study building provided the third significant inhibiting factor for waste minimisation in office refurbishments. Although the building being refurbished is a large office building of twenty two storeys in height with floor average area of $2010 \mathrm{~m}^{2}$ per floor the renovation project was not let to one managing contractor. For the convenience of the building management the project is being split into small, staged and discrete contracts for restricted areas. Consequently the waste stream generated from each individual contract is small and it is not economical to put time into careful disassembly and sorting as it will only yield minor salvageable quantities of materials. The project managers have expressed a desire to see construction waste minimised and Waste Management Plans prepared for each project stage have declared that timber and metals will be recycled. However the tip receipts from the early project stages reveal that all waste was sent to landfill and no measurable quantities separated from the waste stream. Lack of space to sort and store is no doubt also a contributing factor. Economies of scale make recycling practical and profitable. Small separate contracts for parts of a refurbishment project make these economies of scale difficult to achieve.

\section{CONCLUSION}

Most experts consulted for this study agreed that practices in relation to waste generated in Australian commercial refurbishments have improved over recent years. Most experts could identify specific markets that have emerged in the reuse of various materials. However, few respondents could put a value, either cost or benefit impact, on minimising waste. The presence of hazardous materials and specifically asbestos fibres was clearly flagged as a barrier to recycling of the wastes generated from refurbishment. It is evident that remediation of asbestos from buildings scheduled for refurbishment should happen before refurbishment takes place and not concurrently with the renovation works wherever this is possible. Scheduling of refurbishment in a building that must remain occupied during the construction work also strongly limits rates of recycling and reuse. This is due to the time, space and social restrictions likely to occur in the occupied building. Trying to avoid some of these issues by breaking up a large project into small discrete contracts is likely to be unsuccessful in waste minimisation terms as it will likely remove from the contractor's available options those economies of scale which make recycling and reuse profitable.

The construction industry generally remains a high generator of solid waste products and refurbishment projects are a significant part of this waste stream. Waste minimisation strategies in office building refurbishment can 
potentially make a significant contribution to the sustainability of the built environment as a whole. The refurbishment process is part of the loop of resource consumption. Refurbishments extend the useful life of a building thereby allowing continued use of the resources initially expended in its construction. If future life cycles are allowed for, by means of design for deconstruction and disassembly, then the savings generated by refurbishments can be ongoing. Something approaching the cyclic processes of systems in the natural world may eventually be achieved. This can certainly be aimed for as a worthwhile goal. Many of the experts consulted for this study were aware of future possibilities in waste minimisation, it only remains for industry and regulators in partnership to develop a more systematic approach to the dissemination of best practice ideas in construction waste management. The issue of waste minimisation specifically in refurbishment projects has not yet been widely studied. Benchmarks and best practice guidelines are yet to be set in place. Further research is needed to establish the most appropriate practices and targets for this growing sector of the construction industry.

\section{ACKNOWLEDGEMENTS}

The research for this paper was funded by the Australian Cooperative Research Centre for Construction Innovation. The authors would like to thank Angela O'Donnell for her assistance in collecting the data.

\section{REFERENCES}

[1] J. Anderson and K. Mills, "Refurbishment or redevelopment of office buildings? Sustainability comparisons," BRE, London Jul 15, 2002.

[2] C. A. Balaras, K. Droutsa, A. A. Argiriou, and K. Wittchen, "Assessment of energy and natural resources conservation in office buildings using TOBUS," Energy and Buildings, vol. 34, pp. 135153 , February 2002

[3] Jones Lang LaSalle, "Building Refurbishment - Repositioning Your Asset for Success," 2005.

[4] C. S. Poon, A. T. W. Yu, and L. Jaillon, "Reducing building waste at construction sites in Hong Kong.," Construction Management \& Economics, vol. 22, pp. 461-470, 2004.

[5] L. Y. Shen, V. W. Y. Tam, C. M. Tam, and D. Drew, "Mapping approach for examining waste management on construction sites," Construction Engineering and Management, vol. 130, pp. 472-481, July/August 2004

[6] N. Kartam, N. Al-Mutairi, B. Al-Ghusain, and J. Al-Humoud, "Environmental management of construction and demolition waste in Kuwait," Waste Management, vol. 24, pp. 1049-1059, 28 August 2004.

[7] C. T. Formoso, L. Soibelman, and C. De Cesare, "Material waste in building industry: main causes and prevention," Journal of Construction Engineering and Management [H.W. Wilson - AST] vol. 128, p. 316, Jul/Aug 2002.

[8] A. Touart, "Recycling at construction sites.," BioCycle, vol. 39, pp. $53-55,1998$

[9] R. M. Gavilan and L. E. Bernold, "Source evaluation of solid waste in building construction," Journal of Construction Engineering and Management, vol. 120, pp. 536-552, 1994.

[10] M. M. M. Teo and M. Loosemore, "A theory of waste behaviour in the construction industry," Construction Management \& Economics, vol. 19, pp. 741-751, 2001.

[11] A. Seydel, O. D. Wilson, and R. M. Skitmore, "Financial evaluation of waste management methods: a case study," Journal of Construction Research, vol. 3, pp. 167-179, 2002.

[12] C. O. Egbu, "Refurbishment management: challenges and opportunities," Building Research \& Information, vol. 25, pp. 338347, 1997.

[13] S. Andrews, "Waste Wise Construction Program Review: A report to ANZECC," Canberra: Commonwealth Department of the Environment, 1998

[14] H. Lingard, G. Gilbert, and P. Graham, "Improving solid waste reduction and recycling performance using goal setting and feedback," Construction Management \& Economics,, vol. 19, pp. 809-817, 2001.

[15] H. Lingard, P. Graham, and G. Smithers, "Employee perceptions of the solid waste management system operating in a large Australian contracting organization: implications for company policy implementation," Construction Management and Economics, vol. 18, pp. 383-393, 2000.

[16] S. O. Cheung, C. M. Tam, V. Tm, K. Cheung, and H. Suen, "A web-based performance assessment system for environmental protection: We Pass," Construction Management \& Economics, vol. 22, pp. 927-935, 2004.

[17] C. Lockwood, "Building the green way", Harvard Business Review, vol. 84, pp. 129-137, 2006.

[18] S. Khan, M. Hardie, A. O'Donnell, and G. Miller, "The efficacy of waste management plans in Australian commercial construction refurbishment projects " Australian Journal of Construction Economics and Building, vol. 7, pp. 26-36, 2007.

[19] National Occupational Health and Safety Commission, "Guide to the control of asbestos hazards in buildings and structures NOHSC 2002 " National Occupational Health and Safety Commission, Canberra, 1988.

[20] K. W. Chau, S. K. Wong, A. Y. T. Leung, and C. Y. Yiu, "Estimating the value enhancement effects of refurbishment," Facilities, vol. 21, pp. 13-19, February 12, 2003.

[21] P. Mitropoulos and G. A. Howell, "Renovation projects: design process problems and improvement mechanisms," Journal of Management in Engineering, vol. 18, pp. 170-185, 2002. 